\title{
DFT-GIAO Calculation of Properties of ${ }^{19} \mathrm{~F}$ NMR and Stability Study of Environmentally Relevant Perfluoroalkylsulfonamides (PFASAmide)
}

\author{
Rafael Mejía-Urueta, Kleyber Mestre-Quintero and Ricardo Vivas-Reyes* \\ Grupo de Química Cuántica y Teórica, Facultad de Ciencias Exactas y Naturales, \\ Universidad de Cartagena, Cartagena, Colombia
}

\begin{abstract}
Compostos orgânicos perfluorados (POCs), tais como perfluoroctanossulfonato (PFOS) e perfluoralquilsulfonamida (PFASA), são compostos que, recentemente, têm atraído considerável atenção mundial, devido à sua alta persistência e ampla distribuição no ambiente. Entre os métodos espectroscópicos usados para estudar PFASA, ressonância magnética nuclear de ${ }^{19} \mathrm{~F}\left(\mathrm{RMN}{ }^{19} \mathrm{~F}\right)$ é muito eficiente devido à sua habilidade para determinar concentrações de PFASA em amostras biológicas e para medir poluição em amostras de água. Por esta razão, um estudo teórico das propriedades de $\mathrm{RMN}{ }^{19} \mathrm{~F}$ foi realizado. Neste estudo, determinamos a constante de blindagem $(\sigma)$ para diferentes núcleos de flúor das 18 moléculas em estudo, usando teoria do funcional de densidade (DFT) e o método GIAO no nível B3PW91/6-31+G(d,p). Os cálculos de $\sigma$ foram realizados no vácuo e na presença de solvente. Os valores dos deslocamentos químicos $(\delta)$ foram também calculados num nível diferente da teoria. Os melhores resultados foram obtidos com o nível de cálculo DFT-GIAO/B3PW91/6-31+G(d,p), considerando solventes como dimetilsulfóxido (DMSO), clorofórmio $\left(\mathrm{CHCl}_{3}\right)$, acetona $\left(\mathrm{CH}_{3} \mathrm{COCH}_{3}\right)$ e metanol $\left(\mathrm{CH}_{3} \mathrm{OH}\right)$. Os resultados foram interpretados em termos de dureza calculada no nível DFT/B3PW91/6-31+G(d, p). O comportamento da dureza foi maior nas moléculas de quatro carbonos PFASA do que nas de oito carbonos. Isto explica, teoricamente, a resistência de quatro carbonos PFASA para serem transformados em perfluorobutanossulfonato (PFBS).
\end{abstract}

Perfluorinated organic compounds (POCs), such as perfluorooctanesulfonate (PFOS) and perfluoroalkylsulfonamide (PFASA) are compounds that have recently attracted considerable attention worldwide because of its high persistence and wide distribution in the environment. Among the spectroscopic methods used to study the PFASA, ${ }^{19} \mathrm{~F}$ nuclear magnetic resonance $\left(\mathrm{NMR}{ }^{19} \mathrm{~F}\right.$ ) is very effective, due to its ability to determine concentrations of PFASA in biological samples and measure pollution in water samples. For this reason, a theoretical study of the properties of ${ }^{19} \mathrm{~F}$ NMR was performed. In this study we have determined the shielding constant $(\sigma)$ for different fluorine nucleus of the 18 molecules under study, using density functional theory (DFT) and GIAO method with the B3PW91/6-31+G(d,p) level of calculation. The $\sigma$ calculations were made at vacuum and in presence of a solvent. The values of chemical shifts $(\delta)$, were also calculated in a different level of theory. The best results were obtained with the level of calculation DFT-GIAO/B3PW91/6-31+G(d,p) by considering the solvent such as dimethylsulfoxide (DMSO), chloroform $\left(\mathrm{CHCl}_{3}\right)$, acetone $\left(\mathrm{CH}_{3} \mathrm{COCH}_{3}\right)$ and methanol $\left(\mathrm{CH}_{3} \mathrm{OH}\right)$. The results were interpreted in terms of calculated hardness at DFT/B3PW91/6-31+G(d, p) level. The behaviour of the hardness was higher in the molecules of four carbons PFASA than eight carbons. This explain theoretically resistance of four carbons PFAS to be transformed into perfluorobutanesulfonate (PFBS).

Keywords: perfluorinated organic compounds, DFT calculations, hardness, ${ }^{19} \mathrm{~F}$ NMR

\section{Introduction}

Currently, there are a variety of environmental problems mainly generated by the inappropriate and perhaps

*e-mail: rvivasr@unicartagena.edu.co,rafaelmejia05@gmail.com exaggerate use of chemical compounds. Among the many chemical compounds that can affect the environment, exists nowadays a great concern about a group of substances called perfluorinated organic compounds (POCs) and their use have been increasing. ${ }^{1}$ The POCs are characterized by having carbonated chains of variable length, in which 
all the hydrogen atoms have been replaced by fluorine. It is well known that the stability of a compound keeps a closer relationship with its molecular structure. The length of the carbonated chain of an organic compound is one of the parameters that affect the molecular properties related with the stability of these compounds; this fact can bring some changes in the melting point, vapor pressure, hardness softness, electronegativity and other properties.

Nowadays there are not natural sources of POCs, these compounds come from anthropogenic origin, ${ }^{2}$ POCs have been produced over 50 years and have been used in the manufacturing of stain repellents applied to a great variety of consumer products such as fabrics, carpets and paper. They are also used in the manufacturing of many products like paintings, pesticides, adhesives, waxes, polishes, metals and others. ${ }^{3,4}$ There is a great variety of POCs; however, perfluorooctanesulfonate (PFOS) is one of the most important because of its persistence. Due to the high energy of the $\mathrm{C}-\mathrm{F}$ ( $c a .110 \mathrm{kcal} \mathrm{mol}^{-1}$ ) bond, PFOS is resistant to hydrolysis, photolysis, aerobic and anaerobic biodegradation and metabolism by vertebrates. ${ }^{5}$ PFOS is a fully fluorinated anion which is generally used as a salt or incorporated into larger polymer molecules. Compounds structurally related to PFOS have the following molecular formula: $\mathrm{C}_{\mathrm{n}} \mathrm{F}_{2 \mathrm{n}+1} \mathrm{SO}_{2} \mathrm{R}$, where $\mathrm{R}=\mathrm{OH}$ (free acid), $\mathrm{OM}^{+}$ (metal salts), $\mathrm{NH}_{2}$ (sulfonamides) and other derivatives including polymers. ${ }^{6}$

Perfluorobutane sulfonate (PFBS, $\mathrm{C}_{4} \mathrm{~F}_{9} \mathrm{SO}_{3}^{-}$) has been commercialized recently as an alternative to PFOS in a variety of applications. ${ }^{7}$ PFBS is a homologous compound of PFOS that has a four-carbon backbone. The shorter carbon chain makes PFBS less bioaccumulative compared to PFOS. ${ }^{8,9}$

$3 \mathrm{M}$ phased out of manufacturing perfluorooctanesulfonylfluoride (POSF, $\mathrm{C}_{8} \mathrm{~F}_{17} \mathrm{SO}_{2} \mathrm{~F}$ ) based materials after a metabolite and environmental degradation product, perfluorooctanesulfonate (PFOS, $\mathrm{C}_{8} \mathrm{~F}_{17} \mathrm{SO}_{3}{ }^{\circ}$ ), was found to be widespread in human populations and wildlife. ${ }^{10,11}$ Hydrolysis of POSF and metabolic and environmental degradation of $\mathrm{N}$-alkyl derivatives of perfluorooctanesulfonamide, precursors used in various commercial and consumer application technologies, can lead to the formation of PFOS. ${ }^{12,15}$ Similarly, perfluorobutanesulfonate (PFBS, $\mathrm{C}_{4} \mathrm{~F}_{9} \mathrm{SO}_{3}^{-}$) would be expected to be formed from comparable pathways from perfluorobutanesulfonyl fluoride ( $\mathrm{PBSF}, \mathrm{C}_{4} \mathrm{~F}_{9} \mathrm{SO}_{2} \mathrm{~F}$ ) and $\mathrm{N}$-alkyl derivatives of perfluorobutanesulfonamides (PFBSAmides) (Figure 1). ${ }^{9}$

Despite of the previously mentioned vast amount of experimental data in the literature on PFOs and molecular analogs, ${ }^{9-12}$ they are still largely unexplored in some aspect of the fundamental science and a deeper understanding is needed at quantum computational chemistry level in order to gaining insight into fundamental issues such as the electronic structures responsible for stability and chemical behaviour of these kind of molecules. Systematic and consistent theoretical approach to calculate NMR chemical shifts has not yet been published and remains unexplored in the literature. Herein, we performed some theoretical calculations using density functional theory (DFT) to calculate ${ }^{19} \mathrm{~F}$ NMR chemical shifts using gauge-including atomic orbitals (GIAO). ${ }^{13-18}$ ${ }^{19} \mathrm{~F}$ NMR chemical shifts were successfully interpreted on the basis on hardness, and softness concepts.

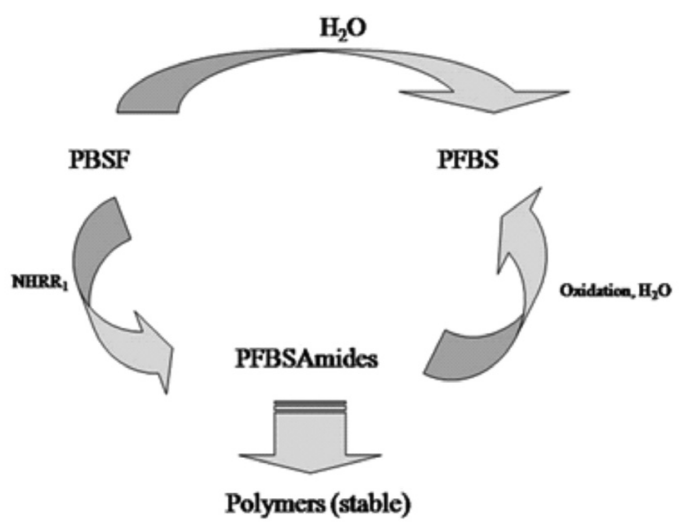

Figure 1. Outline of the production of PBSF-based materials.

\section{Calculations}

The molecules of perfluoroalkylsulfonamide (PFASA) chosen for this study were synthesized by Lehmler et al. ${ }^{10}$ who experimentally obtained the chemical shifts of atoms of fluorine on some perfluorcarbonates compounds. The molecules studied are depicted in the Table 1.

The GAUSSIAN 09 software package was used to carried out the theoretical calculations. ${ }^{19}$ All geometries were completely optimized at the DFT level with the B3PW91 functional, with $6-31+G(d, p)$ basis set. ${ }^{20-22}$ Also, the same functional and basis set were used for the ${ }^{19} \mathrm{~F}$ NMR shielding constants calculations by applying gauge-including atomic orbital (GIAO) method. ${ }^{15,18}$ The effect of solvent on the theoretical NMR parameters was included using the default model SCRF-PCM provided by GAUSSIAN 09.23-25 Dimethylsulfoxide (DMSO), chloroform $\left(\mathrm{CHCl}_{3}\right)$, acetone $\left(\mathrm{CH}_{3} \mathrm{COCH}_{3}\right)$ and methanol $\left(\mathrm{CH}_{3} \mathrm{OH}\right)$ were used as solvents.

\section{Chemical shifts}

All magnetic property calculations were performed using the B3PW91 functional, ${ }^{20,21}$ combined with the 
Table 1. Studied molecules of perfluoroalkylsulfonamide (PFASA)

\begin{tabular}{|c|c|c|c|c|}
\hline \multicolumn{5}{|r|}{$\mathrm{C}_{\mathrm{n}} \mathrm{F}_{2 \mathrm{n}+1} \mathrm{SO}_{2} \mathrm{NR}^{1} \mathrm{R}^{2}$} \\
\hline Molecules & $\mathrm{n}$ & $\mathrm{R}^{1}$ & $\mathrm{R}^{2}$ & PFASA Molecules \\
\hline 1 & 8 & $\mathrm{H}$ & $\mathrm{Me}$ & $\mathrm{N}$-methyl-perfluorooctane-1-sulfonamide \\
\hline 2 & 8 & $\mathrm{H}$ & Et & N-ethyl-perfluorooctane-1-sulfonamide \\
\hline 3 & 4 & $\mathrm{H}$ & $\mathrm{Me}$ & $\mathrm{N}$-methyl-perfluorobutane-1-sulfonamide \\
\hline 4 & 4 & $\mathrm{H}$ & Et & N-ethyl-perfluorobutane-1-sulfonamide \\
\hline 5 & 4 & $\mathrm{H}$ & $\mathrm{CH}_{2} \mathrm{CH}_{2} \mathrm{Ome}$ & $\mathrm{N}$-(2-methoxy-ethyl)-perfluorobutane-1-sulfonamide \\
\hline 6 & 8 & $\mathrm{Me}$ & $\mathrm{Me}$ & $\mathrm{N}, \mathrm{N}$-dimethyl-perfluorooctane-1-sulfonamide \\
\hline 7 & 8 & Et & Et & N,N-diethyl-perfluorooctane-1-sulfonamide \\
\hline 8 & 8 & $\mathrm{Me}$ & Et & N-ethyl-N-methyl-perfluorooctane-1-sulfonamide \\
\hline 9 & 8 & \multicolumn{2}{|c|}{$-\left(\mathrm{CH}_{2}\right)_{2} \mathrm{O}\left(\mathrm{CH}_{2}\right)_{2}-$} & 4-(heptadecafluorooctane-1-sulfonyl)-morpholine \\
\hline 10 & 4 & \multicolumn{2}{|c|}{$-\left(\mathrm{CH}_{2}\right)_{2} \mathrm{O}\left(\mathrm{CH}_{2}\right)_{2}-$} & 4-(nonafluorobutane-1-sulfonyl)-morpholine \\
\hline 11 & 8 & $\mathrm{Me}$ & $\mathrm{CH}_{2} \mathrm{CH}_{2} \mathrm{OH}$ & $\mathrm{N}$-(2-hydroxyethyl)-N-methyl-perfluorooctane-1-sulfonamide (9a) \\
\hline 12 & 8 & Et & $\mathrm{CH}_{2} \mathrm{CH}_{2} \mathrm{OH}$ & N-ethyl-N-(2-hydroxyethyl)-perfluorooctane-1-sulfonamide (9b) \\
\hline 13 & 8 & $\mathrm{Me}$ & $\mathrm{CH}_{2} \mathrm{CH}_{2} \mathrm{OAc}$ & 2-(N-methyl-perfluorooctylsulfonamido) ethylacetate \\
\hline 14 & 8 & Et & $\mathrm{CH}_{2} \mathrm{CH}_{2} \mathrm{OAc}$ & 2-(N-ethyl-perfluorooctylsulfonamido) ethyl acetate \\
\hline 15 & 8 & Et & $\mathrm{CH}_{2} \mathrm{CO}_{2} \mathrm{CH}_{3}$ & methyl 2-(N-ethyl-perfluorooctanesulfonamido) acetate \\
\hline 16 & 8 & Et & $\mathrm{CH}_{2} \mathrm{CO}_{2} \mathrm{H}$ & 2-(N-ethylperfluorooctanesulfonamido)acetic acid \\
\hline 17 & 8 & Et & $\mathrm{CH}_{2} \mathrm{CH}_{2} \mathrm{OTBDMS}$ & perfluorooctane-1-sulfonic acid [2-(tert-butyl-dimethyl-silanyloxi)-ethyl]-ethyl-amide \\
\hline 18 & 8 & $\mathrm{H}$ & $\mathrm{H}$ & perfluorooctane-1-sulfonamide \\
\hline
\end{tabular}

$6-31+\mathrm{G}(\mathrm{d}, \mathrm{p})$ basis set, ${ }^{22}$ both for the full geometry optimizations (the Cartesian coordinates of the equilibrium geometries of all the molecules studied in this work can be obtained from the authors upon request) of each compound and the NMR calculations. The latter were performed using the gauge-including atomic orbital (GIAO) technique..$^{15-18}$

\section{Hardness and softness}

A detailed discussion about the calculation of hardness and softness can be found elsewhere, ${ }^{13,14}$ and only the relevant expressions used for the evaluation of these quantities expressions are given below. The global hardness $(\eta)$ and softness (S), are calculated within DFT as follows:

$\eta=\frac{\mathrm{EI}-\mathrm{AE}}{2}$

Softness is the inverse of hardness

$S=\frac{1}{2 \eta}$

Where $\mathrm{EI}$ and $\mathrm{AE}$ are vertical ionization energy and electron affinity of the systems, respectively. EI and EA were calculated using the following equations:

$$
\begin{aligned}
& \mathrm{EI}=\mathrm{E}_{\text {cation }}-\mathrm{E}_{\text {neutral }} \\
& \mathrm{AE}=\mathrm{E}_{\text {neutral }}-\mathrm{E}_{\text {anion }}
\end{aligned}
$$

We use the expressions 1 and 2 as working equations to obtain the hardness and softness values.

The global hardness can be seen as the resistance of the chemical species to transfer charge or the loss or gain of electrons and the global softness is interpreted as the inverse of global hardness. The general rule is that chemical reactivity and stability of a molecular system evolves towards a state of greater hardness, and hence, its stability increases. The global softness (S), the inverse concept of hardness, is useful for a straightforward prediction of chemical reactivity and stability. In general, it can be said that the increase in softness increases the chemical reactivity and the increase in hardness decreases the chemical reactivity. ${ }^{23-28}$

Similarly, an optimization of the reference compound $\left(\mathrm{CFCl}_{3}\right)$ was made at the same levels of calculation used in the optimization of 18 molecules of PFASA.

\section{Results and Discussion}

\section{Chemical shift calculation}

The fluorine atoms were grouped according to chemical environment in which they were found. These were 
identified according to the carbon atom bound, as shown in Figure 2.

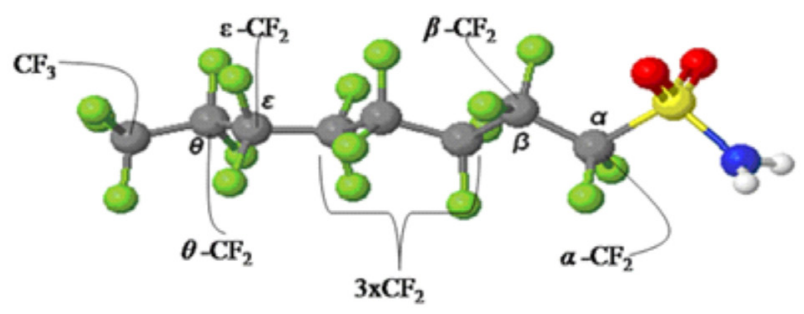

Figure 2. Identification of atoms of fluor according to the position of the carbons.

It is important to note that the experimental value of ${ }^{19} \mathrm{~F}$ chemicals shifts for some of these compounds often depend on the nature of the solvent. All NMR chemical shifts $(\delta)$ are reported by Lehmler et al. ${ }^{10}$ in parts per million (ppm) and were determined relative to $\mathrm{CFCl}_{3}$ for ${ }^{19} \mathrm{~F} \mathrm{NMR}$ spectra.

In such cases, our comparison to experimental data corresponds to the values measured in $\mathrm{CFCl}_{3}$ solvent.

The calculated chemical shifts are expressed as

$\delta^{\text {cal }}($ sample $)=\sigma^{\text {cal }}\left(\mathrm{CFCl}_{3}\right)-\sigma^{\text {cal }}($ sample $)$

where $\sigma^{\text {cal }}\left(\mathrm{CFCl}_{3}\right)$ and $\sigma^{\text {cal }}$ (sample) are the isotropic NMR shieldings of the reference compound $\left(\mathrm{CFCl}_{3}\right)$ and the sample in question, respectively.

The calculated and experimental ${ }^{19} \mathrm{~F}$ chemical shifts values for the total series of molecules studied in this work can be obtained from the authors upon request or as supplementary material.

The theoretical ${ }^{19} \mathrm{~F}$ NMR chemical shifts of the 18 molecules of PFASA were compared with the experimental data. According to these results, the calculated chemical shifts give results that are in good agreement with the experimental values. In order to compare the experimental shifts values with the theoretical shifts values a correlation graphic based on the calculations was made. The correlation values for fluorine chemical shifts are given in Table 2.

Table 2. Comparisons of correlation values $\left(\mathrm{R}^{2}\right)$

\begin{tabular}{ccc}
\hline & $\begin{array}{c}\text { B3PW91/6-31+G(d,p) } \\
\text { vacuum }\end{array}$ & $\begin{array}{c}\text { B3PW91/6-31+G(d,p) } \\
\text { solvent }\end{array}$ \\
\hline correlation values $\left(\mathrm{R}^{2}\right)$ & 0.9956 & 0.9971 \\
\hline
\end{tabular}

We can note that the calculation made by using B3PW91/6-31+G(d,p) in solvent presence, presented a best correlation between experimental data and theoretical ones.

In the appendix are shown the difference between experimental chemical shifts and the calculated values, this difference is called $\Delta \delta$. These values indicate how closer are the calculated theoretical chemical shifts values $\left(\delta^{\text {Teor }}\right)$ from the calculated experimentally $\left(\delta^{\text {Exp }}\right)$. The $\Delta \delta$ were calculated using the following equation:

$\Delta \delta=\delta_{\exp }-\delta_{\text {cal }}$

The $\Delta \delta$ values obtained shown a tendency to diminish when an increase of the functional complexity and the basis was proportionated. The same tendency was observed by considering the solvent presence. This diminish of the $\Delta \delta$ was very positive, because if the $\Delta \delta$ value is smaller, the $\delta_{\text {cal }}$ values will be closer to $\delta_{\text {exp }}$. This can be explained because of the addition of diffuse functions (+) allows that the orbitals occupy a large area in the space. In addition, the presence of polarized functions for heavy atoms (d) and hydrogen atoms (p), add orbitals with angular moments beyond the required to describe each atom in its fundamental state. ${ }^{31}$ Both, the increase of the functionals and the set of basis, give a better description of the properties of the studied system (electronic density and nuclear spin).

This description of the electronic density is because of the inclusion of bigger extension orbitals wich increase the probability to find a number of electrons in a determinated area of the space. This fact brings a better simulation of the nuclear shieldings presented in the nucleus of atoms of flour.

In the same way, when we compare the $\Delta \delta$ values, we can see that better result is obtained when we considered the solvent effect. We assumed that this behaviour was because of an increasing of the $\sigma$ value of fluorine atoms analyzed. This confirms the effect caused by the molecules of the solvent over the nuclear shieldings. The solvents molecules induce a dipolar moment over the solute molecules and this one induce a dipolar moment over the proximity of each solvent molecule resulting a net increasing in the systems dipolar moment, which is directly related with the magnetic field generated by the electrons and cause an increasing in $\sigma$ value.

As stated above the improvements in the simulation of experimental conditions of measure of ${ }^{19} \mathrm{~F}$ NMR lead excellent results using DFT-GIAO/B3PW91/631+G(d,p) level of calculation, with this methodology were obtained results closer to experimental values.

It is well known that the stability of a compound keeps a closer relationship with its molecular structure. The length of the carbonated of a organic compound is one of the parameters that affect the molecular properties related with the stability of a compound, this fact can bring some changes in the melting point, vapor pressure, hardness softness, electronegativity and other properties. 
In Figure 3 are shown the global hardness values calculated for three pairs of molecules which contain the same R group bind to the nitrogen atom, but they differ in the perfluaorated long chain. The global hardness values of the structures were calculated using the equation 1 . The 3, 4, 10 molecules compared with 1, 2,9 molecules have a high hardness (less softness), this situation makes them less polarized and they may have less distortion of their electron cloud, it makes the more stables (least reactive) than their eight carbon analogs.

The PFOS are formed from related substances by microbial environmental degradation or metabolism in

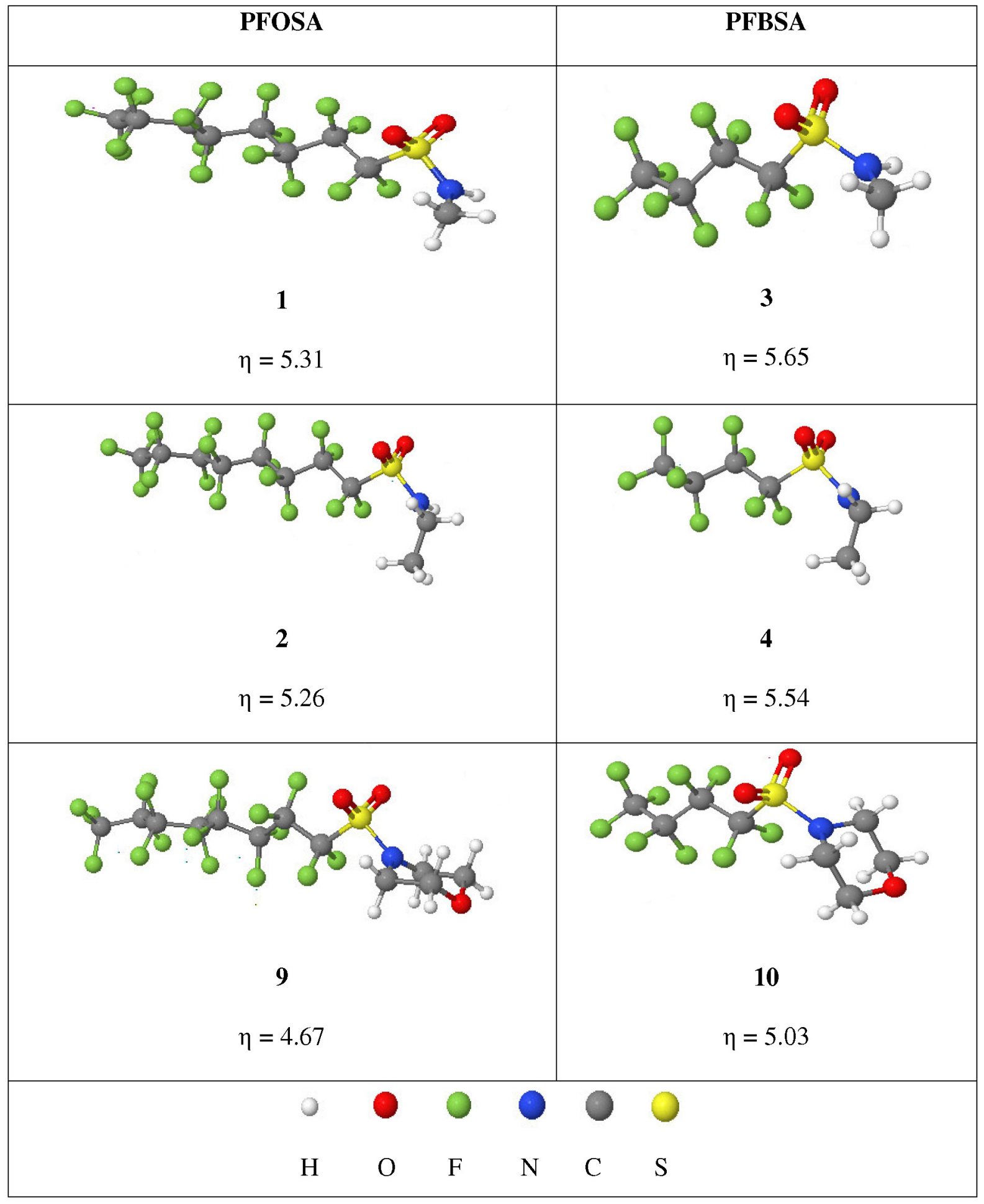

Figure 3. Comparison of hardness $(\eta)$ data for the pairs of molecules 1-3, 2-4 and 9-10. All values are in eV. 
bigger size organisms,${ }^{32}$ it means, molecules that contains the group $\mathrm{C}_{8} \mathrm{~F}_{17} \mathrm{SO}_{3}^{-}$. The PFBS is formed in the same way, but differs with PFOS because it is formed by 4 carbons substances in the perfluorated chain. Based on this, the PFASA of eight carbons will be transformed in PFOS, while four carbons substances will be transformed to PFBS.

Taking in account the hardness data of the six molecules analyzed, the four carbons PFASA have a bigger resistance to be transformed into PFBS than their eight carbons analogs to PFOS, these results are in agreement with many studies where have been demonstrated that PFBS are friendlier chemical compounds with the environment than PFOS because they are less persistent, toxic and bioconcentrated $\left(<1\right.$, almost 3000 times smaller than PFOS) ${ }^{7-9}$

\section{Conclusions}

This paper presents a systematic study of the ${ }^{19} \mathrm{~F}$ chemical shifts for a serie of PFASA compounds. The theoretical predictions of these chemicals shifts of ${ }^{19} \mathrm{~F}$ are in good agreement with experimental results. The results observed with GIAO B3PW91/631+G(d,p) method, when the solvent effect was taking in account. The accuracy of these calculated ${ }^{19} \mathrm{~F}$ chemical shifts is promising for the study of other PFOs molecules analogues. The interpretation of these data via the reactivity descriptors such as hardness, and softness is highly satisfactory.

The analysis of the properties above mentioned shown that the influence of the hardness (softness) values on the stability of these molecules show that the hardness decrease when the length of fluorocarbonated chain is increased. Thus the hardness the four carbons PFASA showed a bigger resistance to be transformed to PFBS than eight carbons analogs to PFOS. This fact and the experimental evidence which shown less persistence, toxicity and bioconcentration of PFBS respect PFOS shown the four carbons PFASA like reasonable alternatives to be used in productive processes.

\section{Acknowledgments}

R. V. R. wishes to thank the Universidad de Cartagena (Cartagena, Colombia) and Colombian Department for Science and Development, Colciencias, for continuous support to his group.

\section{References}

1. Renner, R.; Environ. Sci. Technol. 2001, 35, 154A.

2. Key, B. D.; Howell, R. D.; Criddle, C. S.; Environ. Sci. Technol. 1997, 31, 2445.
3. Richardson, S. D.; Anal. Chem. 2006, 78, 4021.

4. Skutlarek, D.; Exner, M.; Färber, H.; Environ. Sci. Pollut. Res. Int. 2006, 5, 299.

5. Giesy, J. P.; Kannan, K.; Environ. Sci. Technol. 2002, 36, 147A.

6. European Union, 2006; Restrictions on the Marketing and Use of Perfluorooctane Sulfonate; European Parliament legislative resolution on the proposal for a directive of the European Parliament and of the Council relating to restrictions on the marketing and use of perfluorooctane sulfonates (amendment of Council Directive 76/769/EEC) (COM(2005)0618-C60418/2005-2005/0244(COD)). http://www.europarl.europa. eu/sides/getDoc.do?pubRef=-//EP//TEXT+TA+20061025+I TEMS+DOC+XML+V0//EN\&amp;language $=$ EN\#sdocta6, accessed in June 2010.

7. Technical Data Bulletin; Environmental, Health, Safety and Regulatory (EHSR) Profile of Perfluorobutane Sulfonate (PFBS); 3M: St. Paul, MN, 2002. http://solutions.3m. com/3MContentRetrievalAPI/BlobServlet?locale=en_US\&1 $\mathrm{md}=1120194514000 \&$ assetId $=1114270648708 \&$ assetType $=M$ MM_Image\&blobAttribute=ImageFile accessed in June 2010.

8. Martin, J. W.; Muir, D.C.G.; Solomon, K. R. S. A.; Environ. Toxicol. Chem. 2003, 22, 196.

9. Olsen, G.; Chang, S.; Noker, P.; Gorman, G.; Ehresman, D.; Lieder, D.; Butenhoff, J.; Toxicology 2009, 256, 65.

10. Lehmler, H. J.; Rama Rao, V.; Nauduri, D.; Vargo, J. D.; Vargo, S.; J. Fluorine Chem. 2007, 128, 595.

11. Taniyasu, S.; Kannan, K.; Yeung, L. W. Y.; Kwok, K. Y.; Lamc, P. K. S.; Yamashitaa, N.; Anal. Chim. Acta 2008, 619, 221.

12. Liu, P.; Goddard, J. D.; Arsenault, G.; Gu, J.; McAlees, A.; McCrindle, R.; Robertson, V.; Chemosphere 2007, 69, 1213.

13. Geerlings, P.; De Proft, F.; Langenaeker, W.; Chem. Rev. 2003, 103, 1793.

14. Parr, R. G.; Yang, W.; Density Functional Theory of Atoms and Molecules; Oxford University Press: New York, 1989.

15. Helgaker, T.; Jaszunski, M.; Ruud, K.; Chem. Rev. 1999, 103, 8288.

16. London, F.; J. Phys. Radium 1937, 8, 397.

17. Ditchfield, R.; J. Chem. Phys. 1972, 56, 5688.

18. Wolinski, K.; Hinton, J. F.; Pulay, P. J.; J. Am. Chem. Soc. 1990, 112,8251 .

19. Frisch, M. J.; Trucks, G. W.; Schlegel, H. B.; Scuseria, G. E.; Robb, M. A.; Cheeseman, J. R.; Scalmani, G.; Barone, V.; Mennucci, B.; Petersson, G. A.; Nakatsuji, H.; Caricato, M.; Li, X.; Hratchian, H. P.; Izmaylov, A. F.; Bloino, J.; Zheng, G.; Sonnenberg, J. L.; Hada, M.; Ehara, M.; Toyota, K.; Fukuda, R.; Hasegawa, J.; Ishida, M.; Nakajima, T.; Honda, Y.; Kitao, O.; Nakai, H.; Vreven, T.; Montgomery, J. A., Jr.;Peralta, J. E.; Ogliaro, F.; Bearpark, M.; Heyd, J. J.; Brothers, E.; Kudin, K. N.; Staroverov, V. N.; Kobayashi, R.; Normand, J.; Raghavachari, K.; Rendell, A.; Burant, J. C.; Iyengar, S. S.; Tomasi, J.; Cossi, M.; Rega, N.; Millam, N. J.; Klene,M.; 
Knox, J. E.; Cross, J. B.; Bakken, V.; Adamo, C.; Jaramillo, J.; Gomperts, R.; Stratmann, R. E.; Yazyev, O.; Austin, A. J.; Cammi, R.; Pomelli, C.; Ochterski, J. W.; Martin, R. L.; Morokuma, K.; Zakrzewski, V. G.; Voth, G. A.; Salvador, P.; Dannenberg, J. J.; Dapprich, S.; Daniels, A. D.; Farkas, O.; Foresman, J. B.; Ortiz, J. V.; Cioslowski, J.; Fox, D. J.; Gaussian 09, Revision A.1; Gaussian: Wallingford, CT, 2009.

20. Becke, A. D.; J. Chem. Phys. 1993, 98, 5648.

21. Perdew, J. P.; Wang, Y.; Phys. Rev. B: Condens. Matter Mater. Phys. 1992, 45, 13244.

22. Hehre, W. J. Radom, L.; Schleyer, P. R.; Pople, J. A.; Ab Initio Molecular Orbital Theory; Wiley: New York, 1986.

23. Miertus, S.; Scrocco, E.; Tomasi, J.; Chem. Phys. 1981, 55, 117.
24. Cammi, R.; Tomasi, J.; J. Comput. Chem. 1995, 16, 1449.

25. Vivas- Reyes, R; De Proft, F.; Biesemans, M.; Willem, R.; Ribot, F.; Sanchez, C.; Geerlings, P.; New J. Chem. 2002, 26, 1108.

26. Pérez, P.; Toro, P.; Aizman, A.; Contreras, R.; J. Org. Chem. 2002, 67, 4747.

27. Chamorro, E.; Chattaraj, R.; Fuentealba, P.; J. Phys. Chem. A 2003, 107, 7068.

28. Geerlings, P.; De Proft, F.; Langenaekar, W.; Adv. Quantum Chem. 1999, 33, 303.

Submitted: March 17, 2011

Published online: August 23, 2011 